\title{
Response of male and female rats to undernutrition
}

\section{Influence of ovariectomy on partition of nutrients by female rats during undernutrition}

\author{
BY PATRICIA M. HARRIS, R. B. BROADHURST \\ AND DIANE F. HODGSON \\ Applied Biochemistry Division, DSIR, Palmerston North, New Zealand
}

(Received 27 June 1983 - Accepted 23 March 1984)

\begin{abstract}
1. Female Wistar rats ( 5 and 11 weeks old) were either left intact or ovariectomized. Animals of each age- and treatment-group were either ad lib.-fed or undernourished for 4 weeks.

2. The bodies of all animals were analysed for protein and fat and the weights, lipid synthesis rate and lipoprotein lipase (EC 3.1 1.34) activity of four fat depots were determined.

3. The well-nourished ovariectomized animals of both age-groups gained weight more rapidly than the well-nourished intact animals of the same age, but there was no effect of ovariectomy on body composition, lipid synthesis rate or lipoprotein lipase activity in either the well-nourished or the undernourished animals of either age-group.

4. There was a greater efficiency of energy utilization found in the ovariectomized animals than in the intact animals regardless of age or nutritional status.
\end{abstract}

Leshner \& Collier (1973) established that fluctuations in circulating levels of gonadal hormones are associated with alterations in body-weight and composition of normally-fed animals. In female rats oestrogens have been shown to decrease food intake, body-weight and adiposity, while progesterone reverses these effects (Gray \& Wade, 1981). Wade \& Gray (1979) postulated that peripheral metabolic effects of gonadal steroids may be of primary importance in the control of fat deposition, e.g. by influencing triglyceride clearance via lipoprotein lipase (LPL; EC 3 . 1 . 1.34) activity. Although it is unclear what influence these hormones have during times of nutritional stress, several investigators have shown that starvation can substantially reduce adipose tissue LPL activity (e.g. Hietanen \& Greenwood, 1977; Tan et al. 1977). If the hormonal influence on fat deposition is directly metabolic rather than behavioural it would be reasonable to suppose that these hormones could directly influence the partition of nutrients during undernutrition.

In association with a study of the differences between the sexes in their metabolic response to undernutrition (Harris et al. 1984), the effects of undernutrition were compared between intact and ovariectomized animals both before and after puberty.

\section{EXPERIMENT AL}

\section{Experimental animals}

Seventy 10-week-old female Wistar rats were randomly assigned to two groups of thirty-five animals, and seventy 4-week-old animals were also assigned randomly to two groups of thirty-five animals. All animals were trained in meal feeding for $4 \mathrm{~h}$ daily as described by Harris et al. (1984). All animals were given diet MM77 (Farm Products, Palmerston North), weighed daily and individually caged in a room maintained at $21^{\circ}$ with a $12 \mathrm{~h}$ light $-12 \mathrm{~h}$ dark cycle throughout the entire experimental period. At 1 week after allocation to treatment groups, one group of each age underwent complete ovariectomy using a single ventral 
incision under diethyl ether anaesthesia. All ovariectomized $(\mathrm{OvX})$ animals regained the body-weight lost as a result of surgery within 3-4 d. Sham-operated groups were not included in the trial as preliminary trials showed no significant differences in growth rate, food intakes or body composition between sham and intact animals.

The trials commenced 1 week after surgery when the groups of animals reached 12 and 6 weeks of age respectively.

Preliminary groups of seven rats from each of the four treatment groups were killed to act as preliminary controls (intact 12-week-old (12/0I), ovariectomized 12-week-old $(12 / 0 \mathrm{OvX})$, intact 6-week-old $(6 / 0 \mathrm{I})$ and ovariectomized 6-week-old $(6 / 0 \mathrm{OvX}))$. All these groups of animals were meal fed $4 \mathrm{~h}$ before slaughter and at $1 \mathrm{~h}$ before slaughter they were injected intravenously with $1 \mathrm{mCi}^{3} \mathrm{H}_{2} \mathrm{O}$. They were killed and dissected as described by Harris et al. (1984).

The rest of the animals were divided into four groups of seven intact or ovariectomized animals of each age. Two groups each of 12 -week-old intact $(12 / 2 \mathrm{WNI}$ and $12 / 4 \mathrm{WNI})$ and ovariectomized (12/2WNOvX and 12/4WNOvX) and 6-week-old intact $(6 / 2 \mathrm{WNI}$ and 6/4WNI) and ovariectomized (6/2WNOvX and 6/4WNOvX) animals were allowed ad lib. access to the powdered ration for $4 \mathrm{~h}$ daily throughout the trial. The remaining groups of 12-week-old animals (12/2UNI, 12/4UNI, 12/2UNOvX, and 12/4UNOvX) were given amounts of food calculated to reduce their 12-week-old body-weight by one-third over a 4-week period. The 6-week-old animals were too small to survive such a severe weight loss and so the remaining groups of 6-week-old animals (6/2UNI, 6/4UNI, 6/2UNOvX and $6 / 4 \mathrm{UNOvX}$ ) were given amounts of food calculated to hold their body-weights as close as possible to their 6-week-old weight. Groups of intact or ovariectomized animals of each age and level of nutrition were killed 2 weeks after the start of the trial $(12 / 2 \mathrm{WNI}$, $12 / 2$ WNOvX, 12/2UNI, 12/2UNOvX, 6/2WNI, 6/2WNOvX, 6/2UNI and 6/2UNOvX) or 4 weeks after the start of the trial (12/4WNI, 12/4WNOvX, 12/4UNI, 12/4UNOvX, $6 / 4 \mathrm{WNI}, 6 / 4 \mathrm{WNOvX}, 6 / 4 \mathrm{UNI}$, and $6 / 4 \mathrm{UNOvX}$ ). Table 1 shows the final body-weights of all treatment groups. All animals were injected with ${ }^{3} \mathrm{H}_{2} \mathrm{O}$, killed and dissected as described by Harris et al. (1984).

\section{Analytical methods}

The preparation of carcasses and organs for analysis, and the analyses for total fat, crude protein, lipid synthesis rates (LSR) and LPL activity were described by Harris et al. (1984). Urine collections ( $24 \mathrm{~h}$ ) were taken at weekly intervals from animals in each treatment group that underwent the full 4 weeks of the trial. The urine samples were pooled within each treatment group for each week and analysed for nitrogen, creatinine and hydroxyproline as described by Harris et al. (1984).

\section{Calculation of energy output}

The 'energy output' was calculated as the difference between the energy retained or lost from the carcass of the animals and the apparent digestible energy intake as described by Harris et al. (1984).

\section{Statistical methods}

Results were analysed using analysis of variance as described by Harris et al. (1984). Each group sampled contained seven rats. 
Table 1. Mean body-weights of each treatment group 1 week before ovariectomy, and mean terminal body-weights of each treatment group

(Values are means with their standard errors for seven rats)

\begin{tabular}{|c|c|c|c|c|c|}
\hline \multirow{2}{*}{$\begin{array}{l}\text { Treatment } \\
\text { group* }\end{array}$} & \multicolumn{2}{|c|}{$\begin{array}{c}\text { Body-wt } \\
1 \text { week before surgery } \\
(\mathrm{g})\end{array}$} & \multirow{2}{*}{$\begin{array}{c}\text { Age at } \\
\text { termination } \\
\text { (weeks) }\end{array}$} & \multicolumn{2}{|c|}{$\begin{array}{c}\text { Body-wt } \\
\text { at termination } \\
(\mathrm{g})\end{array}$} \\
\hline & Mean & $\mathbf{S E}$ & & Mean & SE \\
\hline $12 / 0 \mathrm{WNI}$ & 220 & 8 & 12 & 233 & 5 \\
\hline 12/0WNOvX & 222 & 5 & 12 & 224 & 6 \\
\hline $12 / 2 \mathrm{WNI}$ & 226 & 6 & 14 & 229 & 5 \\
\hline $12 / 2$ WNOvX & 216 & 6 & 14 & 230 & 6 \\
\hline $12 / 2 \mathrm{UNI}$ & 217 & 5 & 14 & 178 & 3 \\
\hline $12 / 2$ UNOvX & 227 & 7 & 14 & 177 & 4 \\
\hline $12 / 4 \mathrm{WNI}$ & 222 & 8 & 16 & 235 & 7 \\
\hline 12/4WNOvX & 223 & 5 & 16 & 256 & 7 \\
\hline $12 / 4 \mathrm{UNI}$ & 221 & 5 & 16 & 149 & 5 \\
\hline 12/4UNOvX & 226 & 4 & 16 & 152 & 2 \\
\hline 6/0WNI & 52 & 1 & 6 & 105 & 3 \\
\hline 6/0WNOvX & 54 & 2 & 6 & 108 & 3 \\
\hline $6 / 2 \mathrm{WNI}$ & 51 & 2 & 8 & 137 & 2 \\
\hline $6 / 2$ WNOvX & 51 & 3 & 8 & 146 & 8 \\
\hline 6/2UNI & 51 & 2 & 8 & 103 & 5 \\
\hline $6 / 2$ UNOvX & 48 & 2 & 8 & 113 & 2 \\
\hline $6 / 4 \mathrm{WNI}$ & 52 & $\overline{1}$ & 10 & 158 & 5 \\
\hline $6 / 4 W N O v X$ & 52 & 2 & 10 & 181 & 6 \\
\hline 6/4UNI & 51 & 2 & 10 & 112 & 2 \\
\hline 6/4UNOvX & 52 & 1 & 10 & 115 & 2 \\
\hline
\end{tabular}

* Treatment groups are coded such that the first number is the age (weeks) at the start of the trial and the second number is the weeks of treatment undergone where treatments were WNI, well-nourished and intact; WNOvX, well-nourished and ovariectomized; UNI, undernourished and intact; UNOvX, undernourished and ovariectomized.

\section{RESULTS}

Changes in body-weight

Both 6/4WNOvX and 12/4WNOvX gained significantly more $(P<0.05)$ body-weight over the 4-week trial period than the 6/4WNI and 12/4WNI groups respectively (Table 1). Although the ovariectomized animals ate significantly $(P<0.05)$ more food over the entire 4-week trial period (mean with SE: 12/4WNOvX 522 (17) g, 12/4WNI 474 (21) g, $6 / 4 \mathrm{WNOvX} 425(16) \mathrm{g}, 6 / 4 \mathrm{WNI} 387(14) \mathrm{g})$ there were no significant differences $(P>0.05)$ between ovariectomized and intact animals in food intake when the intake was corrected for metabolic body size (Fig. 1). Ovariectomized and intact animals of each age were forced to maintain equal body-weights throughout undernutrition and there were no differences $(P>0.05)$ in the total food intakes of the undernourished ovariectomized animals and the undernourished intact animals in either age-group (mean with SE: 12/4UNOvX 259 (6), 12/4UNI 269 (9), 6/4UNOvX 272 (5), 6/4UNI 270 (6) g/4 weeks).

\section{Excretion of urinary metabolites}

There were no differences in the excretion of $\mathbf{N}$, creatinine or hydroxyproline measured from ovariectomized and intact animals of the same age and the same level of nutrition throughout the trial (Fig. 2). 


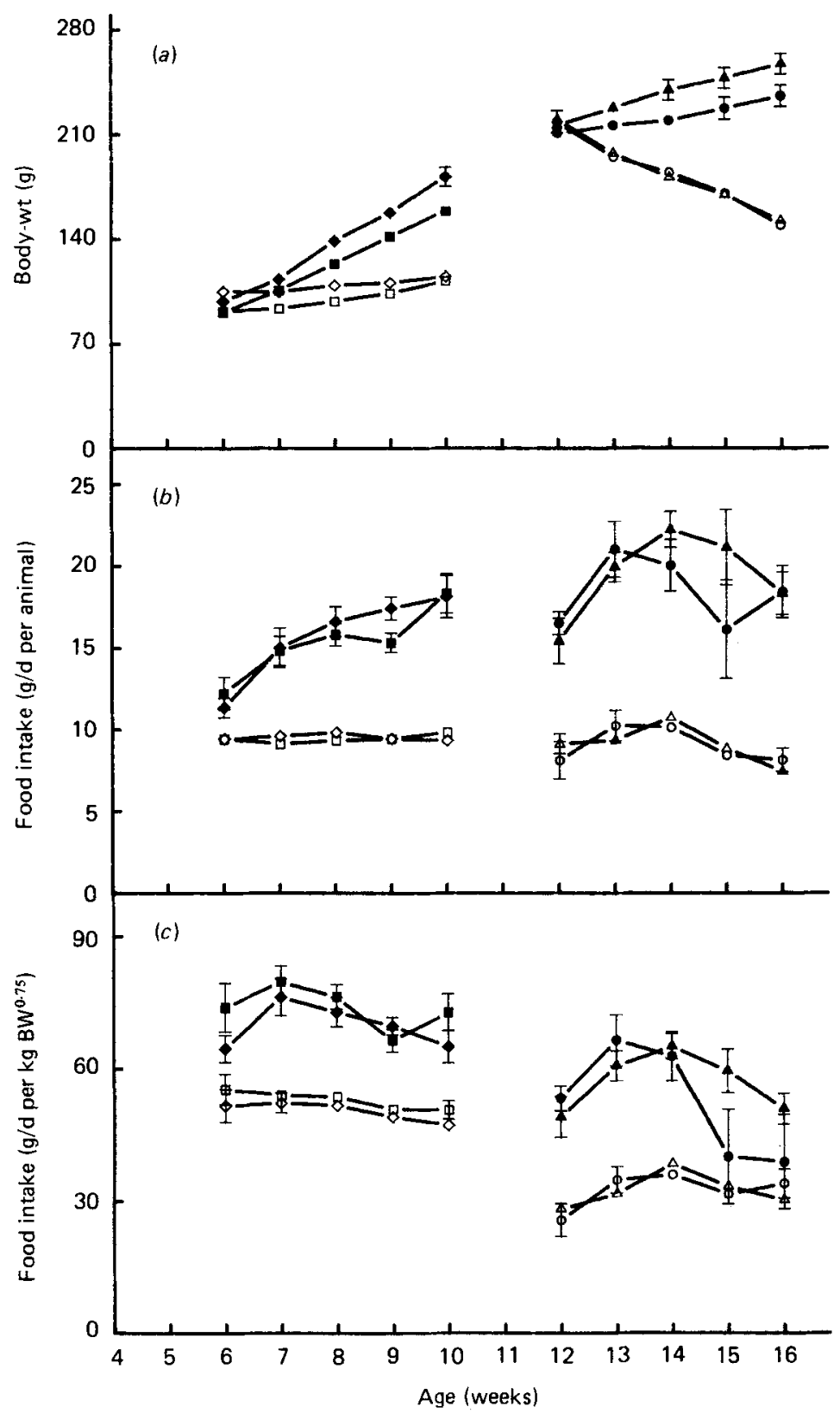

Fig. 1. Curves of (a) growth (mean values with their standard errors $>60),(b)$ daily food intake (mean values with their SE $>0.6$ ) and $(c)$ daily food intake corrected for body-weight $(B W)^{0.75}$ (mean values with their SE $>2 \cdot 0$ ) for ad lib-fed 6-week-old intact females ( $\square$ ), ad lib.-fed 6-week-old ovariectomized females $(\diamond)$, undernourished 6-week-old intact females $(\square)$, undernourished 6-week-old ovariectomized females $(\diamond)$, and ad lib.-fed 12-week-old intact females $(\bigcirc)$, ad lib.-fed 12-week-old ovariectomized females $(\Delta)$, undernourished 12-week-old intact females $(O)$, undernourished 12-week-old ovariectomized females $(\triangle)$, from 6 weeks and 12 weeks of age respectively. 


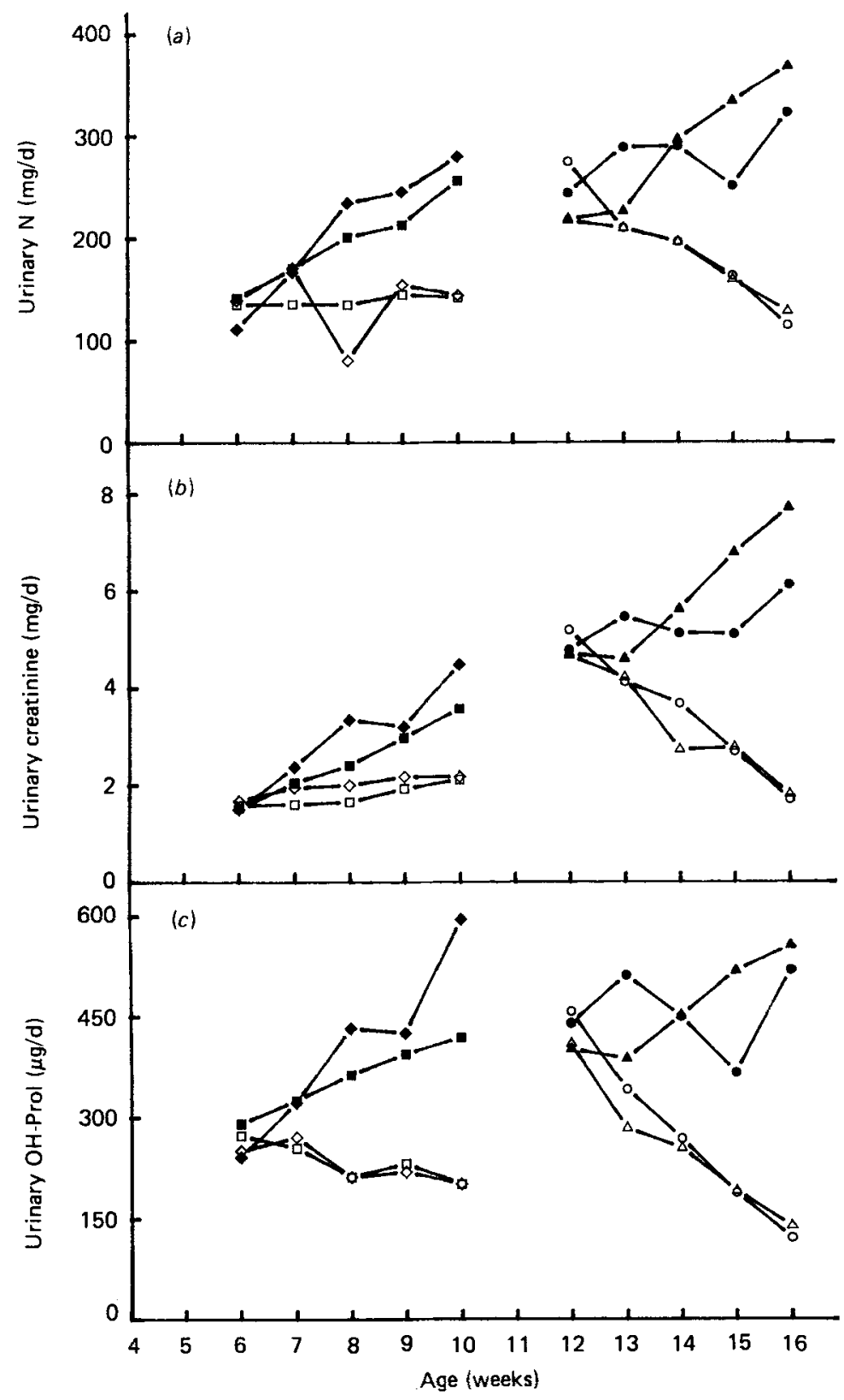

Fig. 2. Curves of $24 \mathrm{~h}$ excretion of ( $a$ ) nitrogen, $(b)$ creatinine and $(c)$ hydroxyproline in the urine (pooled by volume) of ad-lib.-fed 6-week-old intact females ( $\mathbf{E})$, ad lib-fed 6-week-old ovariectomized females $(\bullet)$, undernourished 6-week-old intact females $(\square)$, undernourished 6-week-old ovariectomized females $(\diamond)$, ad lib.-fed 12-week-old intact females (O), ad lib.-fed 12-week-old ovariectomized females (A), undernourished 12-week-old intact females (O), undernourished 12-week-old ovariectomized females $(\triangle)$, from 6 weeks and 12 weeks of age respectively. 
Table 2. Total body protein and total body fat (as a percentage of empty body-weight and on an absolute basis) of ovariectomized or intact rats either ad lib.-fed or undernourished and then killed at various stages of the trial

(Values are means with their standard errors for seven rats)

\begin{tabular}{|c|c|c|c|c|c|c|c|c|}
\hline \multirow{3}{*}{$\begin{array}{l}\text { Treatment } \\
\text { group }\end{array}$} & \multicolumn{4}{|c|}{ Total body protein } & \multicolumn{4}{|c|}{ Total body fat } \\
\hline & \multicolumn{2}{|c|}{$\%$ Empty body-wt } & \multicolumn{2}{|c|}{ g } & \multicolumn{2}{|c|}{$\%$ Empty body-wt } & \multicolumn{2}{|c|}{$\mathrm{g}$} \\
\hline & Mean & SE & Mean & SE & Mean & SE & Mean & SE \\
\hline $12 / 0 \mathrm{WNI}$ & $27 \cdot 4$ & 0.2 & $55 \cdot 4$ & 1.4 & $8 \cdot 3$ & 0.6 & 16.8 & $3 \cdot 3$ \\
\hline $12 / 0 W N O v X$ & $23 \cdot 8$ & 0.2 & $46 \cdot 3$ & 0.8 & $6 \cdot 5$ & 0.5 & $12 \cdot 5$ & 0.9 \\
\hline $12 / 2 \mathrm{WNI}$ & $25 \cdot 5$ & 0.1 & $55 \cdot 5$ & 1.5 & $7 \cdot 9$ & 0.7 & $17 \cdot 2$ & $1 \cdot 6$ \\
\hline $12 / 2 W N O v X$ & $24 \cdot 0$ & $0 \cdot 1$ & $51 \cdot 8$ & $1 \cdot 1$ & $7 \cdot 4$ & 0.6 & 16.0 & $1 \cdot 3$ \\
\hline $12 / 2$ UNI & $22 \cdot 1$ & $0 \cdot 2$ & $38 \cdot 1$ & 0.7 & $3 \cdot 0$ & 0.3 & $5 \cdot 2$ & 0.6 \\
\hline 12/2UNOvX & $20 \cdot 7$ & $0 \cdot 1$ & $35 \cdot 5$ & 0.9 & $2 \cdot 6$ & 0.3 & $4 \cdot 5$ & 0.6 \\
\hline $12 / 4 \mathrm{WNI}$ & $23 \cdot 8$ & 0.2 & $51 \cdot 2$ & 1.4 & $8 \cdot 9$ & 0.6 & $18 \cdot 9$ & $3 \cdot 5$ \\
\hline $12 / 4 W N O v X$ & $24 \cdot 0$ & 0.2 & $57 \cdot 0$ & 1.8 & $9 \cdot 4$ & 0.4 & $22 \cdot 5$ & $1 \cdot 1$ \\
\hline $12 / 4 U N I$ & $25 \cdot 1$ & 0.7 & $34 \cdot 9$ & $1 \cdot 8$ & $2 \cdot 7$ & 0.1 & $3 \cdot 7$ & $1 \cdot 1$ \\
\hline 12/4UNOvX & $27 \cdot 5$ & $0 \cdot 1$ & $39 \cdot 2$ & 0.7 & $1 \cdot 8$ & 0.1 & $2 \cdot 6$ & $0 \cdot 2$ \\
\hline $6 / 0 \mathrm{WNI}$ & $21 \cdot 7$ & 0.2 & $18 \cdot 8$ & 0.6 & $6 \cdot 0$ & 0.4 & $5 \cdot 2$ & 0.5 \\
\hline 6/0WNOvX & $22 \cdot 5$ & 0.1 & $20 \cdot 5$ & 0.7 & 3.8 & 0.5 & $3 \cdot 5$ & 0.5 \\
\hline $6 / 2 \mathrm{WNI}$ & $23 \cdot 2$ & $0 \cdot 1$ & $30 \cdot 5$ & 0.7 & $6 \cdot 5$ & 0.2 & $8 \cdot 6$ & 0.2 \\
\hline $6 / 2$ WNOvX & $18 \cdot 9$ & $0 \cdot 1$ & $26 \cdot 5$ & $2 \cdot 4$ & $7 \cdot 1$ & 0.2 & $10 \cdot 0$ & 0.9 \\
\hline $6 / 2$ UNI & $23 \cdot 3$ & 0.5 & $23 \cdot 8$ & $2 \cdot 2$ & $2 \cdot 8$ & $0 \cdot 1$ & $2 \cdot 8$ & 0.2 \\
\hline $6 / 2$ UNOvX & $24 \cdot 5$ & 0.1 & $26 \cdot 6$ & 0.8 & $3 \cdot 5$ & $0 \cdot 2$ & $3 \cdot 8$ & $0 \cdot 1$ \\
\hline $6 / 4 W N I$ & $21 \cdot 5$ & 0.2 & $32 \cdot 4$ & $1 \cdot 2$ & $9 \cdot 2$ & 0.8 & $14 \cdot 0$ & 1.5 \\
\hline $6 / 4 W N O v X$ & $22 \cdot 6$ & 0.1 & $41 \cdot 0$ & $1 \cdot 6$ & 7.6 & 0.9 & $13 \cdot 1$ & 1.4 \\
\hline $6 / 4$ UNI & $24 \cdot 0$ & 0.2 & $24 \cdot 2$ & 0.5 & $5 \cdot 2$ & $0 \cdot 3$ & $5 \cdot 5$ & $0 \cdot 3$ \\
\hline $6 / 4 U N O v X$ & $23 \cdot 5$ & 0.2 & $25 \cdot 6$ & 0.6 & $6 \cdot 4$ & 0.6 & $7 \cdot 0$ & 0.6 \\
\hline
\end{tabular}

* Treatment groups are coded such that the first number is the age (weeks) at the start of the trial and the second number is the weeks of treatment undergone where treatments were WNI, well-nourished and intact; WNOvX, well-nourished and ovariectomized; UNI, undernourished and intact; UNOvX, undernourished and ovariectomized.

\section{Changes in body composition}

Table 2 shows the changes in body protein and fat in each treatment group during the trial, both as a percentage of body-weight and on an absolute basis. The ovariectomized animals of both ages had a lower weight and proportion of body fat $(P<0.05)$ at the start of the trial than the intact animals of the same age. This suggests that ovariectomized animals may not have recovered completely from surgery by this stage even though their body-weights appeared to be normal. However, 2 weeks from the start of the trial all the well-nourished ovariectomized animals had the same proportion of body fat as intact animals of the same age $(P>0 \cdot 05)$. Because the well-nourished ovariectomized animals were larger by the end of the trial than the intact animals of the same age, there were differences in absolute levels of body fat and protein between these treatment groups. However, after 4 weeks of the trial there were no differences in the proportions of either body fat or body protein in the carcasses of well-nourished ovariectomized and intact animals of the same age. Equally after 4 weeks of undernutrition the ovariectomized animals in both age-groups showed no differences in the proportions of body fat or body protein from that in the carcasses of intact animals of the same age. This suggests that on a gross level the ovariectomized and intact animals derived the same proportions of endogenous energy from body protein and fat during undernutrition. This is also reflected in the weights of the individual fat depots 
Table 3. Weights $(\mathrm{g})$ of adipose tissue at four depots sampled from ovariectomized or intact rats ad lib.-fed or undernourished at various stages of the trial

(Values are means with their standard errors for seven rats)

\begin{tabular}{|c|c|c|c|c|c|c|c|c|}
\hline \multirow{2}{*}{$\begin{array}{l}\text { Treatment } \\
\text { group* }\end{array}$} & \multicolumn{2}{|c|}{ Abdominal } & \multicolumn{2}{|c|}{ Scapular } & \multicolumn{2}{|c|}{ Perirenal } & \multicolumn{2}{|c|}{ Parametrial } \\
\hline & Mean & SE & Mean & SE & Mean & $\mathrm{SE}$ & Mean & SE \\
\hline $12 / 0 \mathrm{WNI}$ & $1 \cdot 59$ & $0 \cdot 20$ & 0.82 & 0.04 & $1 \cdot 14$ & $0 \cdot 14$ & $1 \cdot 23$ & $0 \cdot 10$ \\
\hline $12 / 0$ WNOvX & $1 \cdot 33$ & 0.11 & 0.74 & 0.05 & 0.92 & 0.09 & 0.74 & 0.09 \\
\hline $12 / 2 \mathrm{WNI}$ & 1.78 & $0 \cdot 19$ & 0.95 & 0.08 & $1 \cdot 28$ & $0 \cdot 27$ & $1 \cdot 31$ & $0 \cdot 26$ \\
\hline $12 / 2$ WNOvX & $1 \cdot 87$ & 0.22 & 0.94 & 0.07 & 0.99 & 0.11 & $1 \cdot 19$ & 0.22 \\
\hline $12 / 2$ UNI & 0.78 & 0.08 & 0.54 & 0.04 & 0.21 & 0.04 & 0.29 & 0.09 \\
\hline $12 / 2$ UNOvX & 0.51 & 0.04 & 0.55 & 0.01 & $0 \cdot 19$ & 0.02 & $0 \cdot 14$ & 0.01 \\
\hline $12 / 4 \mathrm{WNI}$ & 1.95 & 0.20 & $1 \cdot 05$ & 0.03 & $1 \cdot 20$ & $0 \cdot 10$ & 2.06 & 0.30 \\
\hline $12 / 4 W N O v X$ & $2 \cdot 17$ & 0.08 & $1 \cdot 21$ & 0.03 & $1 \cdot 32$ & 0.16 & 1.57 & 0.19 \\
\hline 12/4UNI & 0.48 & 0.04 & 0.39 & 0.03 & 0.08 & 0.01 & 0.09 & 0.01 \\
\hline 12/4UNOvX & 0.53 & 0.05 & 0.41 & 0.02 & 0.07 & 0.01 & 0.07 & 0.01 \\
\hline 6/0WNI & 0.61 & 0.06 & $0 \cdot 38$ & 0.03 & $0 \cdot 10$ & 0.03 & 0.09 & 0.02 \\
\hline 6/0WNOvX & 0.51 & 0.07 & 0.34 & 0.03 & 0.09 & 0.02 & 0.05 & 0.01 \\
\hline $6 / 2 \mathrm{WNI}$ & $1 \cdot 28$ & 0.08 & 0.67 & 0.03 & 0.33 & 0.03 & 0.47 & 0.06 \\
\hline $6 / 2$ WNOvX & $1 \cdot 33$ & $0 \cdot 10$ & $0 \cdot 65$ & 0.03 & 0.37 & 0.07 & 0.32 & 0.06 \\
\hline $6 / 2 \mathrm{UNI}$ & 0.54 & 0.06 & $0 \cdot 35$ & 0.01 & 0.07 & 0.01 & $0 \cdot 10$ & 0.03 \\
\hline 6/2UNOvX & 0.68 & 0.05 & 0.41 & 0.05 & $0 \cdot 10$ & 0.01 & 0.08 & 0.02 \\
\hline $6 / 4 \mathrm{WNI}$ & $1 \cdot 78$ & 0.25 & 0.89 & 0.07 & 0.50 & 0.09 & 0.83 & $0 \cdot 14$ \\
\hline $6 / 4 W N O v X$ & 2.04 & 0.22 & 0.88 & 0.08 & 0.64 & 0.11 & 0.68 & 0.13 \\
\hline 6/4UNI & 0.87 & 0.05 & 0.48 & 0.01 & $0 \cdot 13$ & 0.01 & $0 \cdot 17$ & 0.02 \\
\hline 6/4UNOvX & 0.96 & $0 \cdot 12$ & 0.52 & 0.28 & 0.17 & 0.03 & $0 \cdot 12$ & 0.02 \\
\hline
\end{tabular}

* Treatment groups are coded such that the first number is the age (weeks) at the start of the trial and the second number is the weeks of treatment undergone where treatments were WNI, well-nourished and intact; WNOvX, well-nourished and ovariectomized; UNI, undernourished and intact; UNOvX, undernourished and ovariectomized.

(Table 3) which after 2 and 4 weeks of the trial show no significant differences $(P>0.05)$ between ovariectomized and intact animals of either age at the same level of nutrition.

\section{Fat depot metabolism}

The LSR and LPL activities of each depot for each group of animals are shown in Tables 4 and 5. Changes in LSR and LPL activities were parallel as a result of ovariectomy and undernutrition at the different depots.

Both LSR and LPL activities were lower in the 12-week-old animals than in the 6-week-old animals and lower in the undernourished animals than in the well-nourished animals for the measurements for the complete depot. Ovariectomy caused a reduction of both LSR and LPL activities in preliminary animals, presumably an indication that recovery from surgery was not complete at this stage. After 2 weeks for LSR and 4 weeks for both LSR and LPL activities there were no consistent differences between the well-nourished ovariectomized animals and the well-nourished intact animals of the same age. There were also no differences in either LSR or LPL activities between the undernourished ovariectomized and the undernourished intact animals of the same age. If the LSR and LPL activities were considered on a rate (or activity) per unit weight tissue basis, instead of total weight of individual depots, then the undernourished animals had a higher rate (or activity) than the well-nourished animals in both age-groups. However, there were still no consistent or significant $(P>0.05)$ differences between ovariectomized and intact animals of either age at 2 and 4 weeks into the trial period. 
Table 4. Lipid synthesis rate (disintegrations/min $\times 10^{3}$ per total site), as measured by incorporation of ${ }^{3} \mathrm{H}_{2} \mathrm{O}$ by four fat depots, from ovariectomized or intact rats either ad lib.-fed or undernourished and killed at various stages of the trial

(Values are means with their standard errors for seven rats)

\begin{tabular}{|c|c|c|c|c|c|c|c|c|}
\hline \multirow{2}{*}{$\begin{array}{l}\text { Treatment } \\
\text { group* }^{*}\end{array}$} & \multicolumn{2}{|c|}{ Abdominal } & \multicolumn{2}{|c|}{ Scapular } & \multicolumn{2}{|c|}{ Perirenal } & \multicolumn{2}{|c|}{ Parametrial } \\
\hline & Mean & $\mathrm{SE}$ & Mean & $\mathrm{SE}$ & Mean & SE & Mean & $\mathrm{SE}$ \\
\hline $12 / 0 \mathrm{WNI}$ & $38 \cdot 9$ & $3 \cdot 3$ & $102 \cdot 9$ & $10 \cdot 3$ & 59.7 & 6.6 & $50 \cdot 2$ & 1.9 \\
\hline $12 / 0$ WNOvX & $37 \cdot 0$ & $5 \cdot 7$ & $89 \cdot 2$ & $9 \cdot 1$ & $42 \cdot 4$ & $4 \cdot 8$ & $18 \cdot 2$ & $2 \cdot 4$ \\
\hline $12 / 2 \mathrm{WNI}$ & $63 \cdot 3$ & $10 \cdot 3$ & $119 \cdot 4$ & $14 \cdot 6$ & $82 \cdot 3$ & $14 \cdot 6$ & $63 \cdot 8$ & $12 \cdot 6$ \\
\hline $12 / 2$ WNOvX & $70 \cdot 4$ & $5 \cdot 8$ & $112 \cdot 4$ & $28 \cdot 7$ & $72 \cdot 9$ & $18 \cdot 3$ & $52 \cdot 5$ & $8 \cdot 1$ \\
\hline $12 / 2$ UNI & $22 \cdot 4$ & $5 \cdot 1$ & $45 \cdot 1$ & $6 \cdot 3$ & $18 \cdot 8$ & $3 \cdot 3$ & $24 \cdot 6$ & $4 \cdot 6$ \\
\hline $12 / 2$ UNOvX & $18 \cdot 5$ & $4 \cdot 4$ & $40 \cdot 7$ & 8.4 & $20 \cdot 2$ & $3 \cdot 5$ & $11 \cdot 2$ & $2 \cdot 7$ \\
\hline $12 / 4 \mathrm{WNI}$ & $56 \cdot 1$ & 10.6 & $116 \cdot 6$ & $16 \cdot 1$ & 63.6 & $16 \cdot 0$ & $82 \cdot 6$ & $15 \cdot 1$ \\
\hline 12/4WNOvX & $86 \cdot 3$ & $11 \cdot 3$ & $128 \cdot 0$ & $9 \cdot 4$ & 60.9 & $6 \cdot 5$ & $71 \cdot 4$ & $14 \cdot 2$ \\
\hline $12 / 4 \mathrm{UNI}$ & $6 \cdot 5$ & $4 \cdot 2$ & $38 \cdot 6$ & $21 \cdot 6$ & $4 \cdot 1$ & $2 \cdot 4$ & $2 \cdot 3$ & $1 \cdot 2$ \\
\hline 12/4UNOvX & $9 \cdot 0$ & $3 \cdot 1$ & $16 \cdot 3$ & $2 \cdot 8$ & $6 \cdot 5$ & 3.0 & $4 \cdot 3$ & 0.9 \\
\hline $6 / 0 \mathrm{WNI}$ & $174 \cdot 1$ & $106 \cdot 1$ & $128 \cdot 5$ & $75 \cdot 0$ & 41.9 & $27 \cdot 3$ & $28 \cdot 3$ & $14 \cdot 2$ \\
\hline $6 / 0$ WNOvX & $53 \cdot 3$ & $5 \cdot 2$ & $59 \cdot 6$ & $4 \cdot 7$ & $9 \cdot 1$ & $8 \cdot 2$ & $3 \cdot 3$ & $5 \cdot 5$ \\
\hline $6 / 2 \mathrm{WNI}$ & $89 \cdot 8$ & $10 \cdot 6$ & $116 \cdot 3$ & $20 \cdot 7$ & $29 \cdot 9$ & $7 \cdot 2$ & $35 \cdot 0$ & $3 \cdot 2$ \\
\hline 6/2WNOvX & $99 \cdot 1$ & $10 \cdot 4$ & $80 \cdot 7$ & $9 \cdot 7$ & $34 \cdot 6$ & $7 \cdot \overline{8}$ & $27 \cdot 5$ & $4 \cdot 2$ \\
\hline $6 / 2 \mathrm{UNI}$ & $52 \cdot 7$ & $10 \cdot 1$ & $53 \cdot 5$ & $4 \cdot 8$ & $14 \cdot 1$ & $2 \cdot 0$ & - & - \\
\hline $6 / 2$ UNOvX & $61 \cdot 6$ & 8.8 & $57 \cdot 6$ & $8 \cdot 3$ & $16 \cdot 6$ & $10 \cdot 2$ & $10 \cdot 9$ & $3 \cdot 4$ \\
\hline $6 / 4 \mathrm{WNI}$ & $127 \cdot 5$ & $15 \cdot 0$ & $142 \cdot 7$ & $15 \cdot 5$ & $47 \cdot 2$ & $5 \cdot 2$ & $69 \cdot 9$ & $8 \cdot 5$ \\
\hline $6 / 4$ WNOvX & $153 \cdot 7$ & $15 \cdot 7$ & 155.9 & $22 \cdot 4$ & 64.8 & 6.9 & $59 \cdot 8$ & $4 \cdot 9$ \\
\hline $6 / 4 U N I$ & $79 \cdot 8$ & $10 \cdot 7$ & 55.9 & $3 \cdot 3$ & $20 \cdot 7$ & 1.6 & $24-9$ & $3 \cdot 4$ \\
\hline 6/4UNOvX & $84 \cdot 9$ & $13 \cdot 1$ & $51 \cdot 8$ & $7 \cdot 4$ & $20 \cdot 8$ & $1 \cdot 5$ & $12 \cdot 1$ & $2 \cdot 0$ \\
\hline
\end{tabular}

* Treatment groups are coded such that the first number is the age (weeks) at the start of the trial and the second number is the weeks of treatment undergone where treatments were WNI, well-nourished and intact; WNOvX, well-nourished and ovariectomized; UNI, undernourished and intact; UNOvX, undernourished and ovariectomized.

\section{Energy output}

Estimates of total 'energy output' and 'energy output' corrected for lean body mass (LBM) are shown in Table 6 for the eight groups of animals that were alive until the end of the 4-week trial period. The energy output of the well-nourished animals was greater than that of undernourished animals $(P<0.05)$, although when 'energy output' was corrected for LBM this difference was no longer significant. However, the more prominent difference was the significantly higher energy outputs, corrected for LBM $(P<0.05)$, of the intact animals compared with the ovariectomized animals regardless of age or level of nutrition.

\section{DISCUSSION}

Wade \& Gray (1979) suggested that ovariectomy influences the amount of fat stored in the body, and thus total body-weight, by altering LPL activity in adipose tissue. This hypothesis was based on the separate observations of several workers: (1) withdrawal of ovarian hormones by ovariectomy induces hyperphagia and rapid weight gain lasting approximately 1 month after surgery (Tartellin \& Gorski, 1973); (2) ovariectomy was found to double carcass fat content (Leshner \& Collier, 1973) and this change in fat content accounted for most of the change in body-weight; (3) ovariectomy was shown to increase LPL activity per g adipose tissue (Hamosh \& Hamosh, 1975).

In the present work ovariectomy carried out either before or after puberty resulted in 
Table 5. Lipoprotein lipase (EC 3. 1. 1.34) activity ( $m U /$ total site) in four fat depots from ovariectomized and intact rats either ad lib.fed or undernourished and killed as preliminary controls or at the end of the 4 week trial period

(Values are means with their standard errors for seven rats)

\begin{tabular}{|c|c|c|c|c|c|c|c|c|}
\hline \multirow{2}{*}{$\begin{array}{l}\text { Treatment } \\
\text { group* }^{*}\end{array}$} & \multicolumn{2}{|c|}{ Abdominal } & \multicolumn{2}{|c|}{ Scapular } & \multicolumn{2}{|c|}{ Perirenal } & \multicolumn{2}{|c|}{ Parametrial } \\
\hline & Mean & SE & Mean & SE & Mean & SE & Mean & $\mathrm{SE}$ \\
\hline $12 / 0 \mathrm{WNI}$ & $6 \cdot 3$ & 0.9 & $13 \cdot 2$ & 1.4 & $6 \cdot 5$ & $1 \cdot 5$ & $4 \cdot 3$ & $1 \cdot 2$ \\
\hline $12 / 0$ WNOvX & $4 \cdot 3$ & 0.4 & $7 \cdot 7$ & 0.9 & $4 \cdot 5$ & 0.7 & $2 \cdot 8$ & 0.3 \\
\hline $12 / 4$ WNI & $7 \cdot 8$ & 1.9 & $17 \cdot 2$ & $2 \cdot 6$ & $11 \cdot 5$ & 1.9 & 18.9 & 3.9 \\
\hline $12 / 4 W N O v X$ & $14 \cdot 3$ & $1 \cdot 2$ & $17 \cdot 9$ & $1 \cdot 1$ & $14 \cdot 4$ & $2 \cdot 6$ & $16 \cdot 2$ & $3 \cdot 4$ \\
\hline 12/4UNI & $1 \cdot 2$ & 0.5 & $13 \cdot 3$ & 0.6 & - & - & - & - \\
\hline 12/4UNOvX & $3 \cdot 3$ & 0.5 & $12 \cdot 7$ & $1 \cdot 0$ & - & - & - & - \\
\hline $6 / 0 \mathrm{WNI}$ & $5 \cdot 5$ & 0.8 & 4.9 & 0.5 & - & - & - & - \\
\hline 6/0WNOvX & $6 \cdot 4$ & 0.9 & $4 \cdot 9$ & $0 \cdot 4$ & - & - & - & - \\
\hline $6 / 4 \mathrm{WNI}$ & $19 \cdot 5$ & $3 \cdot 4$ & 13.9 & $1 \cdot 1$ & $7 \cdot 1$ & 1.8 & 10.5 & $2 \cdot 5$ \\
\hline $6 / 4$ WNOvX & $27 \cdot 4$ & $3 \cdot 2$ & $16 \cdot 2$ & $2 \cdot 1$ & $11 \cdot 2$ & $1 \cdot 7$ & $10 \cdot 8$ & $3 \cdot 2$ \\
\hline $6 / 4 U N I$ & $11 \cdot 2$ & $2 \cdot 1$ & 11.9 & $1 \cdot 1$ & - & - & - & - \\
\hline 6/4UNOvX & $12 \cdot 1$ & $1 \cdot 8$ & $9 \cdot 6$ & 0.7 & - & - & - & - \\
\hline
\end{tabular}

* Treatment groups are coded such that the first number is the age (weeks) at the start of the trial and the second number is the weeks of treatment undergone where treatments were WNI, well-nourished and intact; WNOvX, well-nourished and ovariectomized; UNI, undernourished and intact; UNOvX, undernourished and ovariectomized.

Table 6. Total energy output* $(J)$ and energy output corrected for lean body mass $(J / g)$ for ovariectomized or intact Wistar rats either ad lib.fed or undernourished for the complete 4 week trial period

(Valves are means with their standard errors for seven rats)

\begin{tabular}{|c|c|c|c|c|}
\hline \multirow{2}{*}{$\begin{array}{l}\text { Treatment } \\
\text { group } \dagger\end{array}$} & \multicolumn{2}{|c|}{ Total energy output } & \multicolumn{2}{|c|}{$\frac{\text { Energy output }}{\text { Lean body mass }}$} \\
\hline & Mean & SE & Mean & $\mathrm{SE}$ \\
\hline $6 / 4 \mathrm{WNI}$ & 3985 & 126 & $29 \cdot 1$ & $1 \cdot 0$ \\
\hline 6/4WNOvX & 4303 & 201 & $27 \cdot 3$ & $1 \cdot 0$ \\
\hline 6/4UNI & 3135 & 88 & $31 \cdot 0$ & 0.7 \\
\hline 6/4UNOvX & 2185 & 238 & $22 \cdot 0$ & $2 \cdot 1$ \\
\hline $12 / 4 \mathrm{WNI}$ & 5680 & 230 & $29 \cdot 5$ & 10 \\
\hline $12 / 4 W N O v X$ & 5805 & 171 & $26 \cdot 7$ & 0.5 \\
\hline $12 / 4 U N I$ & 4219 & 125 & $32 \cdot 6$ & $1 \cdot 5$ \\
\hline 12/4UNOvX & 3905 & 88 & $27 \cdot 8$ & 0.6 \\
\hline
\end{tabular}

* For calculation of energy output, see p. 308.

$\dagger$ Treatment groups are coded such that the first number is the age (weeks) at the start of the trial and the second number is weeks of treatment undergone where treatments were WNI, well-nourished and intact; WNOvX, well-nourished and ovariectomized; UNI, undernourished and intact; UNOvX, undernourished and ovariectomized.

body-weight gain and this was associated with a slight increase in food intake. Yet at no stage was a corresponding change found in the proportion of the carcass which was protein or fat for the ovariectomized animals compared with intact animals of the same age. Ovariectomy has been demonstrated repeatedly to cause an increased rate of weight gain, whether it is carried out in very young (Slob \& Bosch, 1975) or adult (Roy \& Wade, 1977) 
rats. While it is generally accepted that ovariectomy causes fatter rats, the work of Leshner \& Collier (1973) is one of the few examples where increased percentage body fat has been demonstrated in association with the increase in weight gain. It is perhaps relevant that increased weight gain itself can result in increased fatness, especially in older rats (e.g. Harris, 1980). Gray \& Wade (1981) showed little, if any, change in the proportions of carcass fat as a result of ovariectomy. Because of this, it could be argued that the losses of body fat shown as a result of oestrogen administration to ovariectomized rats in their work were merely a reflection of lowered food intake rather than a direct metabolic effect. Changes in LPL activity are known to reflect changes in food intake with a consequent change in circulating triglyceride (e.g. Hietanen \& Greenwood, 1977), and so only by controlling differences in food intake could direct metabolic effects be measured.

Although no changes were found in the proportions of carcass protein and fat as a result of ovariectomy, there were effects on absolute amounts of body protein, especially during undernutrition. The 12-week-old ovariectomized animals lost significantly less body protein during the 4 weeks of undernutrition than intact animals of the same age and the 6-week-old ovariectomized animals generally had more body protein throughout the trial than intact 6-week-old animals.

Interpretation of these results is confused by the lower weights of both carcass protein and fat in the 12-week-old ovariectomized animals at the start of the trial, thus suggesting that recovery from surgery may not have been complete in these animals when the trial commenced. Therefore, comparisons of the effects of ovariectomy can only be validly made between animals at equal times after surgery. It has been demonstrated that rat skeletal muscle contains cytoplasmic oestrogen receptors as well as androgen receptors (Dubé $e t$ al. 1976). Thus, like adipose tissue, muscle is a potential target organ for direct oestrogen activity. If muscle were a target organ, ovariectomy could influence muscle protein synthesis as well as the supply of oxidizable substrates via lipolysis. However, while there were differences in carcass protein between ovariectomized and intact animals, both 6- and 12-week-old undernourished ovariectomized rats had the same body-weights, food intakes and daily $\mathrm{N}$ and creatinine excretion as intact animals of the same age throughout the trial. Consequently, ovariectomy had no effect on $\mathbf{N}$ balance or muscle mass during undernutrition and it seems likely that the changes in carcass protein are a reflection of different body-weights rather than a direct influence on carcass composition.

The results of the present work are very similar to those of Perry et al. (1979) who showed no significant differences in body composition associated with the rapid weight gain of rats ovariectomized at $23 \mathrm{~d}$ of age. In the present trial the lower energy output found in ovariectomized rats compared with intact rats is similar to the lower food conversion ratios (g feed/g live-weight gain) found by Perry et al. (1979) for ovariectomized animals. This increased efficiency in both the ovariectomized animals of Perry et al. (1979) and the present work, regardless of level of feeding, would support the suggestion of Wade \& Gray (1979) that removal of gonadal hormones by ovariectomy has a more direct metabolic effect rather than an indirect effect through appetite control. However, it does not appear that any such metabolic effect is directed only at fat storage in the animal but rather a more general effect, perhaps an influence on basal metabolic rate.

It is apparent from the present work that there can be large differences between the fat depots in LPL activity. There were also differences in the changes of LPL activity between the fat depots due to nutritional stress. LPL activity has generally been reported on an activity per $\mathrm{g}$ tissue basis (e.g. Hamosh \& Hamosh, 1975; Ramirez, 1981). If there is a reduction in fat storage, LPL activity on a per $g$ tissue basis may be elevated above control levels while overall LPL activity for the entire depot is reduced, as occurred in the present work. The work of Hamosh \& Hamosh (1975) which showed a doubling of LPL activity 
with ovariectomy did not define the site of sampling for the adipose tissue and reported the information on a per $g$ tissue basis with no indication of total depot weight. In the present work neither the de novo synthesis of triglyceride nor the LPL activity appeared to be influenced by the ovariectomy of either well-nourished or undernourished rats. This is not altogether surprising as fat deposition itself did not appear to be affected disproportionately by ovariectomy.

The authors would like to thank the Analytical Services Group, Applied Biochemistry Division for performing the carcass analyses and some of the urine analyses, and also Dr D. W. Dellow for assistance with the surgery.

\section{REFERENCES}

Dubé J. Y., Lesage, R. \& Tremblay, R. R. (1976). Canadian Journal of Biochemistry 54, 50-55.

Gray, J. M. \& Wade, G. N. (1981). American Journal of Physiology 240, E474-E481.

Hamosh, M. \& Hamosh, P. (1975). Journal of Clinical Investigation 55, 1132-1135.

Harris, P. M. (1980). British Journal of Nutrition 43, 15-26.

Harris, P. M., Hodgson, D. F. \& Broadhurst, R. B. (1984). British Journal of Nutrition 52, 289-306.

Hietanen, E. \& Greenwood, M. R. C. (1977). Journal of Lipid Research 18, 480-490.

Leshner, A. I. \& Collier, G. (1973). Physiology and Behaviour 11, 671-676.

Perry, B. N., McCracken, A., Fur, B. J. A. \& MacFie, H. J. H. (1979). Journal of Endocrinology 81, 35-48.

Ramirez, I. (1981). American Journal of Physiology 240, E533-E538.

Roy, E. J. \& Wade, G. N. (1977). Hormones and Behaviour 8, 265-274.

Slob, A. K. \& Bosch, J. J. (1975). Physiology and Behaviour 14, 353-361.

Tan, M. H., Sata, T. \& Havel, R. J. (1977). Journal of Lipid Research 18, 363-370.

Tartellin, M. F. \& Gorski, R. A. (1973). Acta Endocrinologica 72, 551-568.

Wade, G. N. \& Gray, J. M. (1979). Physiology and Behaviour 22, 583-593. 